\title{
A bout of voluntary running enhances context conditioned fear, its extinction, and its reconsolidation
}

\author{
Joyce Siette, Amy C. Reichelt, and R. Frederick Westbrook ${ }^{1}$ \\ School of Psychology, University of New South Wales, Sydney NSW 2034, Australia
}

\begin{abstract}
Three experiments used rats to examine the effect of a single bout of voluntary activity (wheel running) on the acquisition, extinction, and reconsolidation of context conditioned fear. In Experiment 1 , rats provided with access to a wheel for $3 \mathrm{~h}$ immediately before or after a shocked exposure to a context froze more when tested in that context than rats provided with access to the wheels $6 \mathrm{~h}$ after the shocked exposure or rats not provided with access to the wheels. In Experiment 2 , rats provided with access to the wheels immediately before or after a nonshocked exposure to the conditioned context froze less when tested in that context than rats provided with access to the wheels $6 \mathrm{~h}$ after the nonshocked exposure or rats not provided with access to the wheels. In Experiment 3, rats provided with access to wheels immediately after an extended nonshocked exposure to the conditioned context again froze less, whereas rats provided with access to the wheels after a brief nonshocked exposure froze more on the subsequent test than sedentary controls. These results show that a single bout of running can enhance acquisition, extinction, and reconsolidation of context conditioned fear.
\end{abstract}

Pavlovian conditioned fear is thought to contribute to anxiety disorders such as post-traumatic stress, and extinction of this fear is a goal of exposure-based treatments of post-traumatic stress disorder (Bouton et al. 2001). Hence, there has been interest in identifying variables that regulate the acquisition and extinction of fear responses in animal models in order to better understand posttraumatic stress and develop more effective treatments for this disorder. One of the variables that influence the acquisition of conditioned fear in rodents is a history of exercise. Rodents provided with access to running wheels for several weeks and then shocked in a distinctive context exhibit more fear (typically freezing responses) than sedentary controls (Baruch et al. 2004; Burghardt et al. 2004, 2006; Van Hoomissen et al. 2004; Clark et al. 2008; Kohman et al. 2011). This increase in conditioned fear is consistent with running-induced improvements in learning and memory found in other tasks, such as the Morris water maze (O'Callaghan et al. 2007; Gomes da Silva et al. 2012).

Enhanced fear conditioning has also been observed when the wheels that had been present were removed $1 \mathrm{~d}$ before conditioning and the subsequent test (Van Hoomissen et al. 2004). This suggests that running immediately before or after conditioning is not necessary for the enhanced conditioning; rather, a history of running per se is sufficient for that enhancement. A history of running leads to various changes in hippocampal plasticity that could mediate these improvements in learning and memory. These changes include increased neurogenesis and levels of brainderived neurotrophic factor (BDNF), fibroblast growth, and insulin-like growth factors, as well as increases in acetylcholine, opiate, and monoamine neurotransmitters (Neeper et al. 1996; van Praag et al. 1999, 2005; Greenwood et al. 2003, 2011; Liu et al. 2008; Strong et al. 2011).

In contrast to its effects on acquisition of context fear, a history of running failed to influence extinction of this fear. Greenwood et al. (2009) provided rats with running wheels for 6 wk, subjected them to context fear conditioning, and then, while still providing access to the wheels, tested the rats under extinc-

\footnotetext{
${ }^{1}$ Corresponding author

E-mail f.westbrook@unsw.edu.au

Article is online at http://www.learnmem.org/cgi/doi/10.1101/lm.032557.113.
}

tion each day across several days for their levels of fear (freezing). These investigators reported that rats provided with access to the wheels froze more than the sedentary controls when tested under extinction the day after conditioning, confirming that exercise had enhanced learning and/or consolidation of the contextshock association. However, the two groups did not differ in the rate at which freezing was suppressed across the subsequent extinction tests. This was in spite of the fact that the rats in the exercising group had access to the wheels across the testing days, indicating that voluntary exercise had failed to enhance fear suppression. These investigators also failed to detect an effect on extinction when exercise began after context fear conditioning. Specifically, rats were conditioned to fear a context and provided with access to wheels for $1 \mathrm{wk}$ or $6 \mathrm{wk}$, then repeatedly exposed to the context in the absence of shock while still having access to the wheels in their home cages. Neither group of rats differed from sedentary controls in the rate at which freezing declined across the context alone exposures. Thus, 1 wk or $6 \mathrm{wk}$ of wheel access before extinction and continued access to the wheels across daily extinction sessions failed to enhance the rate at which freezing declined to the conditioned context.

As noted previously, running immediately before or after a shocked exposure to a context is not necessary for enhanced conditioning. However, this conclusion does not exclude the possibility that running immediately before or after fear conditioning can also enhance fear conditioning even in the absence of a prior history of running. As far as we are aware this possibility has not been examined. However, there is some evidence that a single bout of exercise can enhance long-term memory in people. For example, a single bout of exercise before and after training improved free recall on a delayed test (Coles and Tomporowski 2008); a single bout of intense running after training enhanced retention of a motor skill (Roig et al. 2012); and a single bout of post-training aerobic exercise increased recall for positive emotional images in both elderly patients with normal cognition and those with mild

(C) 2014 Siette et al. This article is distributed exclusively by Cold Spring Harbor Laboratory Press for the first 12 months after the full-issue publication date. After 12 months, it is available under a Creative Commons License (Attribution-NonCommercial 3.0 Unported), as described at http:// creativecommons.org/licenses/by-nc/3.0/. 
cognitive impairment (Segal et al. 2012). The present experiments used rats to examine the effects of a single bout of running on context fear conditioning, its extinction, and its reconsolidation.

\section{Results}

\section{Experiment 1: effect of wheel running on the consolidation} of conditioned fear

This experiment examined the effect of exercise on the acquisition and consolidation of context conditioned fear. All rats were shocked in a chamber and tested there the following day for their levels of freezing. Rats were allocated to four experimental groups. Rats in Group R-Pre had access to running wheels (R) in their home cages for $3 \mathrm{~h}$ immediately prior to contextual fear conditioning. Group R-Post had 3-h access to the wheels immediately post conditioning. Group R-Post $6 \mathrm{~h}$ had 3 -h access to the wheels $6 \mathrm{~h}$ following conditioning. Group NR were provided with locked wheels for $3 \mathrm{~h}$ post conditioning, but were not allowed to run (No Running).

As shown in Figure 1, no significant differences were observed between the groups in the levels of post-shock freezing $\left(F^{\prime} \mathrm{s}<1.0\right)$. During the retention test, statistical analysis confirmed that rats provided with access to the wheels immediately before (Group R-Pre) or after (Group R-Post) conditioning froze significantly more on that test than those provided with access to the wheels $6 \mathrm{~h}$ after conditioning (Group R-Post $6 \mathrm{~h}$ ) or rats provided with access to locked wheels and, therefore, not allowed to run (Group NR) $\left(F_{(1,28)}=6.3, F_{\mathrm{c}}=4.196\right)$. There were no significant differences between the levels of freezing among rats in Groups R-Pre and R-Post or among rats in Groups R-Post $6 \mathrm{~h}$ and NR $\left(F^{\prime} \mathrm{s}<2.0\right)$.

As illustrated in Figure 2A, there were no significant differences between the distances run by rats in the three groups $\left(F_{(1,21)}<1\right)$. However, as illustrated in Figure $2 \mathrm{~B}$, there was a positive relation between distance covered and the test levels of freezing $\left(R^{2}=0.55, P=0.03\right)$.

\section{Summary}

This experiment demonstrated that a single, 3-h access to a running wheel either before or immediately after contextual fear conditioning resulted in increased levels of freezing on the subsequent retention test, indicating that running had enhanced memory acquisition and consolidation. To further investigate the effects of acute voluntary exercise we sought to establish the effects of exercise on the extinction (Experiment 2) and reconsolidation (Experiment 3 ) of an established memory. Reconsolidation is thought to be an adaptive update mechanism enabling
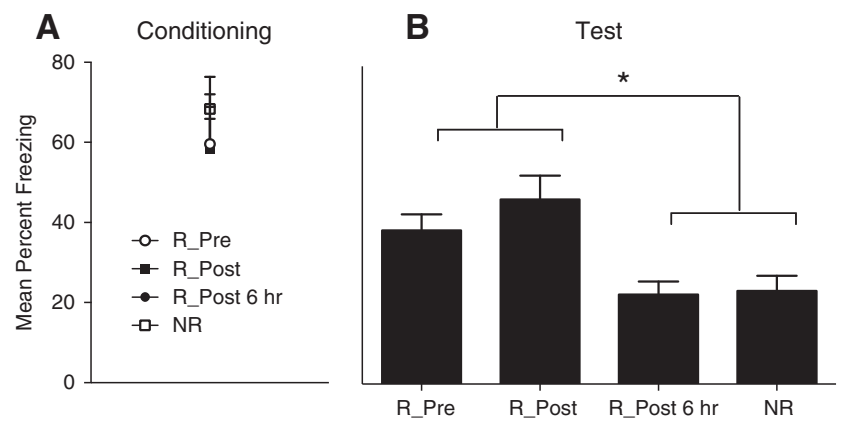

Figure 1. Mean percent freezing (+SEM) at post conditioning $(A)$ and during the test $(B)$ in rats exposed to exercise prior to extinction (R_Pre), immediately post extinction (R_Post), $6 \mathrm{~h}$ post extinction (R_Post $6 \mathrm{~h}$ ), or no exercise (NR). $\left({ }^{*}\right) P<0.05$. the incorporation of new information into the reactivated memory (Lee 2009), whereas extinction leads to the formation of a long-lasting new inhibitory memory that competes with the original memory trace (Eisenberg et al. 2003; Duvarci and Nader 2004). Retrieval of a consolidated memory renders it susceptible to disruption by amnesic agents (Nader et al. 2000; Sara 2000) and thus physical exercise may also impact on this process. Consequentially, we sought to establish whether exercise impacts upon the extinction and reconsolidation of an established context-shock memory.

\section{Experiment 2: effect of wheel running on the extinction of conditioned fear}

This experiment examined the effect of a single bout of running on extinction of context conditioned fear. All rats were shocked 3 min after placement in the chamber and then exposed to that chamber in the absence of shock on the following day. Rats in Group R-Pre were provided with running wheels in their home cages for $3 \mathrm{~h}$ before this extinction session, while those in Group R-Post were provided with wheels for $3 \mathrm{~h}$ immediately after the extinction session. Rats in Group R-Post $6 \mathrm{~h}$ were allowed $3 \mathrm{~h}$ access to the wheels $6 \mathrm{~h}$ after extinction, while those in Group NR were not allowed access to the wheels. One day after the extinction session, all rats were returned to the chamber and tested for 10 min under extinction.

Conditioning was successful (Fig. 3). All rats froze after the shock and there were no statistically significant differences in the levels of freezing among the groups $\left(F^{\prime} \mathrm{s}<1.0\right)$. The statistical analysis of extinction revealed a significant quadratic trend $\left(F_{(1,28)}=12.1\right)$. Inspection of the figure suggests that this trend was due to an increase in freezing that reached a peak around the time when shock had been presented followed by a decrease in freezing across the latter part of the session. There were no significant differences among the groups or any significant group $x$ trend interactions $\left(F^{\prime} \mathrm{s}<2\right)$, indicating that access to the wheels (Group R-Pre) immediately prior to extinction failed to produce any detectable effect on freezing. The statistical analysis of the retention test showed that rats provided with access to the wheels either before (Group R-Pre) or after (Group R-Post) extinction froze significantly less than rats provided with access to the wheels $6 \mathrm{~h}$ after extinction (Group R-Post $6 \mathrm{~h}$ ) or rats not provided with access to the wheels (Group NR) $\left(F_{(1,14)}=5.54\right)$. There were no statistically significant differences between the levels of freezing among rats in Groups R-Pre and R-Post $\left(F_{(1,14)}=2.8\right)$, or between rats in Groups R-Post $6 \mathrm{~h}$ and NR $\left(F_{(1,14)}=1.9\right)$.

Figure 4 shows the mean distance covered by rats in the three groups. There were no significant differences among the groups in the distance covered $\left(F^{\prime} \mathrm{s}<1\right)$. However, there was a significant negative correlation between the distance covered and the test levels of freezing $\left(R^{2}=0.61, P=0.02\right)$.

\section{Experiment 3: effect of wheel running on the reconsolidation of conditioned fear}

Retrieval of a memory is thought to destabilize the original trace, thereby allowing the incorporation of new information, and the process of reconsolidation is required to restabilize the trace. This process of reconsolidation can be enhanced or impaired, resulting in better or worse retention of the memory (Lee 2009). Experiment 3 sought to replicate the beneficial effect of exercise on consolidation of the extinction memory observed in the previous experiment and to determine whether exercise also enhanced reconsolidation of the context fear memory. The design consisted in training rats to fear a context and then reexposing them to the context in the absence of shock for either $90 \mathrm{sec}$ or $14 \mathrm{~min}$. The 

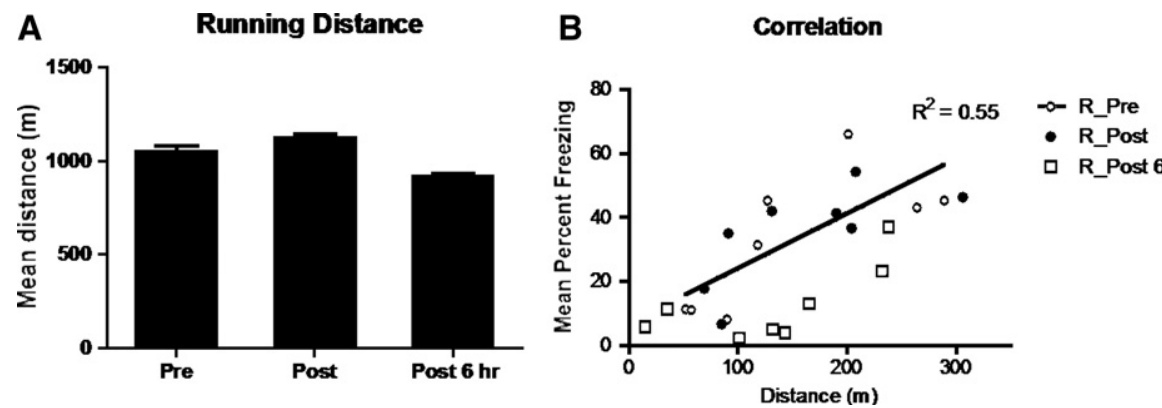

Figure 2. (A) There were no significant running distance differences between animals in rats exposed to exercise prior to extinction (Pre), immediately post extinction (Post), $6 \mathrm{~h}$ post extinction (Post $6 \mathrm{~h}$ ). (B) Running distance and correlation of distance $(\mathrm{m})$ to mean percent freezing at test. It was demonstrated that running distance was positively correlated with freezing, which indicated that greater running distances lead to increased levels of freezing, indicative of enhanced memory acquisition or consolidation.

\section{Discussion}

These experiments have shown that a single bout of voluntary exercise (running) can enhance context conditioned fear, its extinction, and its reconsolidation. In Experiment 1, rats provided with access to the wheels for $3 \mathrm{~h}$ immediately before or after a shocked exposure to the context froze more when tested in that context $24 \mathrm{~h}$ later than rats provided with access to the wheels $6 \mathrm{~h}$ after the shocked exposure or rats not allowed to run in the wheels. In Experiment 2, rats provided with this access to the wheels immediately before or after a nonshocked exposure to the conditioned context froze less on the subsequent test than rats provided with access to the brief (90 sec) reexposure was followed by access to the wheels for likewise followed by access to the wheels for $3 \mathrm{~h}$ or no such access.

Rats received two conditioning sessions spaced $24 \mathrm{~h}$ apart. This was performed in order to increase the levels of context conditioned fear and thereby increase the likelihood of detecting differences on the final test between rats given a brief or extended extinction session. Each conditioning session consisted in administering shock $3 \mathrm{~min}$ after placement in the context and removing the rats $3 \mathrm{~min}$ after the shock. A significant linear trend in the levels of post-shock freezing was observed on the first $\left(F_{(1,45)}=98.31\right.$, $P<0.05)$ and second $\left(F_{(1,45)}=183.43, P<0.05\right)$ conditioning sessions. There were no statistically significant between-group differences in the levels of freezing across the conditioning sessions $(P>0.05)$ (see Fig. 5). There were no statistically significant differences in levels of freezing between the two groups that received the brief $(90 \mathrm{sec})$ nonshocked reexposure to the context or between those that received the extended (14 min) nonshocked reexposure $\left(F^{\prime} \mathrm{s}<1\right)$.

At test, a significant main effect of duration of the extinction session was observed $\left(F_{(1,45)}=13.59, P<0.05\right)$, indicating that brief exposure to the context evoked greater levels of freezing compared to extended context reexposure. No significant effect of exercise was observed overall $(F<1)$. However, a significant interaction was observed $\left(F_{(1,45)}=4.38, P<0.05\right)$, which, from inspection of the figure, was due to exercise exerting contrasting effects depending on the duration of the extinction session. Simple effects analysis confirmed that rats given a brief context reexposure and allowed access to the wheels froze significantly more than those not allowed access to the wheels $\left(F_{(1,22)}\right.$ $=14.63, P<0.05)$, whereas rats provided with access to the wheels following the extended reexposure froze significantly less than those not allowed access to the nificant differences in running distance were observed between exercising groups (average $=2398.58 \pm 85.76 \mathrm{~m}$ ) as shown in Figure 6. There was a significant positive relation between distance covered and the test levels of freezing among rats reexposed to the context for a brief duration $\left(R^{2}=0.4243, P<0.05\right)$, and a significant negative relation between distance covered and test levels of freezing among rats exposed to the context for an extended duration $\left(R^{2}=0.3294, P<0.05\right)$. $\left({ }^{*}\right) P<0.05$. $3 \mathrm{~h}$ or no such access and the extended $(14 \mathrm{~min})$ reexposure was wheels $\left(F_{(1,22)}=5.419, P<0.05\right)$. No sig- wheels $6 \mathrm{~h}$ after the nonshocked exposure and rats not allowed to run in the wheels. Moreover, in both experiments rats provided with the delayed access to the wheels and rats not allowed to run in the wheels did not differ in their test levels of freezing. Thus, running per se on the day of conditioning or extinction did not increase or decrease, respectively, the subsequent test levels of freezing, showing that any muscular effects and their motoric consequences (e.g., fatigue) produced by running did not affect the test levels of freezing. Rather, the critical condition for these contrasting effects on subsequent freezing was that running occurred in close temporal proximity to the conditioning or extinction episode. Moreover, this running interacted directly with the nature of these exposures: in Experiment 1, the distance covered in the wheels before or after the shocked exposure was positively correlated with the subsequent test levels of freezing; in Experiment 2 , the distance covered before or after the nonshocked exposure was negatively correlated with the test levels of freezing.

Experiment 3 replicated the enhanced extinction of context conditioned fear among rats that were provided with access to the wheels immediately after an extended nonshocked exposure to the conditioned context; these rats froze less on the subsequent retention test than rats that were not allowed to run in the wheels. This experiment additionally found that the single bout of running immediately after a brief nonshocked exposure to the conditioned context enhanced reconsolidation of the context-shock association; these rats froze more on the subsequent retention test than rats not allowed to run after that brief nonshocked exposure. These contrasting effects of running on the subsequent test levels of freezing again show that any physical consequences

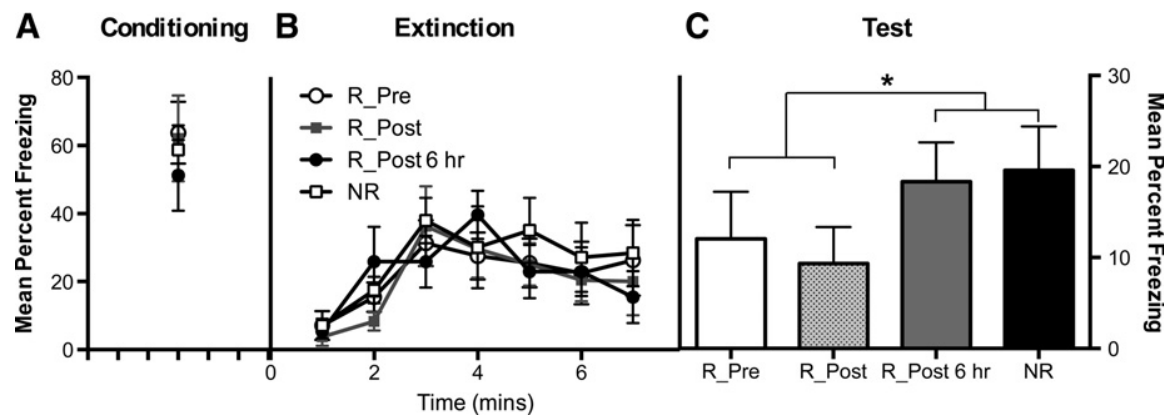

Figure 3. Mean percent freezing ( + SEM) during final minute post conditioning $(A)$, across extinction trials $(B)$, and averaged across test trials $(C)$ in rats exposed to exercise prior to extinction (R_Pre), immediately post extinction (R_Post), $6 \mathrm{~h}$ post extinction (R_Post $6 \mathrm{~h}$ ), or no exercise (NR). 

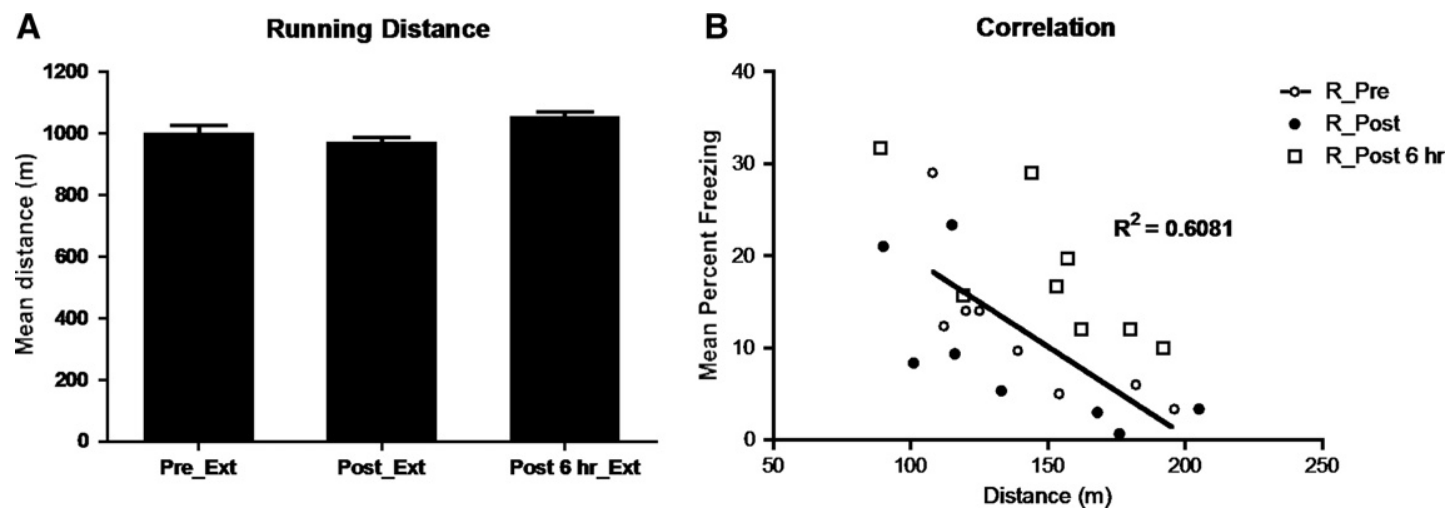

Figure 4. Mean running distances in experimental groups ( + SEM) were shown to be negatively correlated with mean percent levels of freezing at test in rats exposed to exercise prior to extinction (Pre_Ext), immediately post extinction (Post_Ext), $6 \mathrm{~h}$ post extinction (Post $6 \mathrm{~h}$ Ext), indicating that greater running distances $(A)$ lead to decreased levels of freezing $(B)$.

of running (e.g., fatigue) did not produce any detectable effect on subsequent freezing. Moreover, running again interacted with the nature of the learning experience; distance covered in the run after the extended nonshocked exposure was negatively correlated with the test levels of freezing; distance covered in the run after the brief nonshocked exposure was positively correlated with the test levels of freezing.

Previous studies have shown that rodents provided with access to wheels for several weeks prior to contextual fear conditioning exhibit more freezing than sedentary controls when subsequently tested in that context (Baruch et al. 2004; Clark et al. 2008). This increased freezing has been found when access to the wheels continued across the subsequent tests and when that access was terminated prior to testing, suggesting that the history of exercise before conditioning was sufficient for the increased levels of freezing across subsequent testing. One of the changes induced by a history of exercises is increased BDNF in the hippocampus. BDNF plays an important role in synaptic plasticity and hippocampal-dependent forms of learning and memory (van Praag et al. 1999; Vaynman et al. 2004). Hence, increased levels of BDNF could constitute a mechanism underlying the effects of a history of running on context fear conditioning. Levels of BDNF are also elevated by a single bout of aerobic exercise in both mice and people. Specifically, Rasmussen et al. (2009) reported that mouse brains analyzed for BDNF mRNA expression following treadmill exercise exhibited a three- to fivefold increase in BDNF mRNA expression in the hippocampus and cortex, peaking $2 \mathrm{~h}$ after the termination of exercise. These investigators also studied eight human volunteers who rowed for several hours while simultaneous blood samples were obtained from the radial artery and the internal jugular vein. Analysis revealed that BDNF increased two- to threefold during exercise. Therefore, this mechanism could also underlie the enhanced acquisition, extinction, and reconsolidation observed in the present experiments.

Memory consolidation is the process in which newly acquired information is processed from a labile state into a lasting trace. The labile state following training suggests that a period of consolidation that lasts for several hours can allow for memories to be impaired or enhanced. Following context-shock exposure there is an early period that lasts $\sim 4 \mathrm{~h}$ during which cellular processes, including stimulation of glutamatergic NMDA-type glutamate receptors and calcium ion influx into the cell, can be disrupted and memory consolidation impaired (Bourtchouladze et al. 1998). NMDA receptors have been shown to mediate the initial consolidation of a memory to form a long-term trace within the hippocampal CA1 region, supported by the demonstration of impaired acquisition of contextual-fear conditioning in CA1 NMDA receptor knockout mice (Shimizu et al. 2000). The process

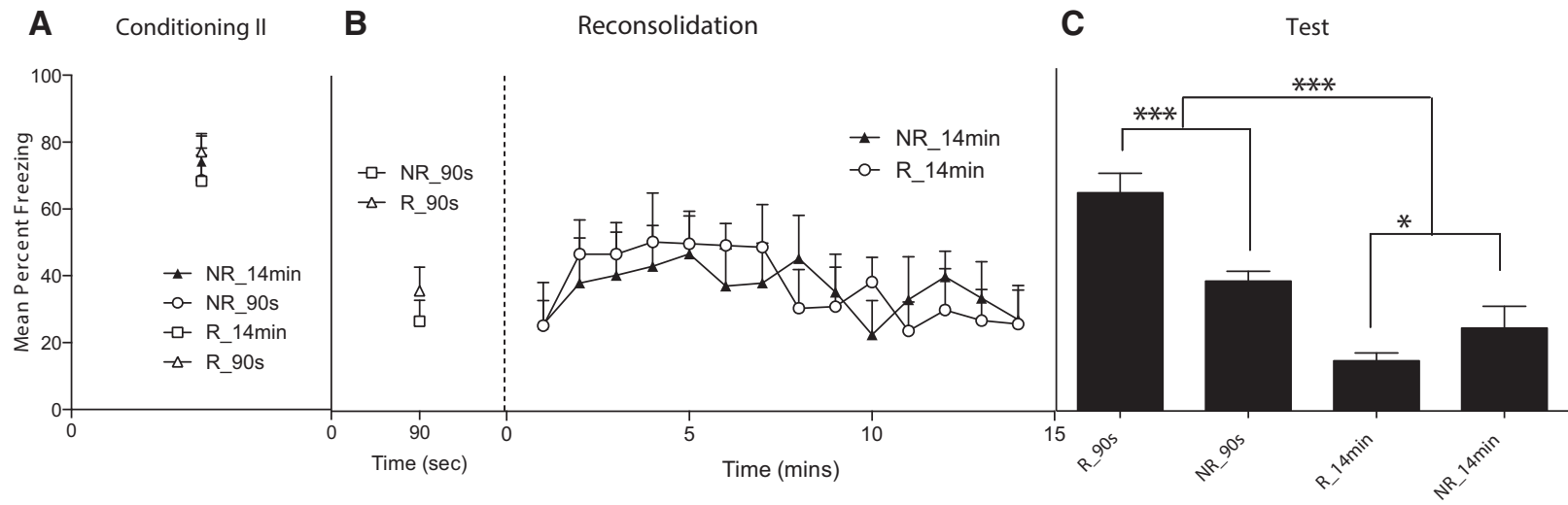

Figure 5. There were no group differences during the two conditioning sessions and there were no exercise differences when averaged across chamber reexposure. Animals that were exposed for $90 \mathrm{sec}$ had higher levels of freezing compared to the other groups. In the sedentary controls, brief reexposure to the context results in higher levels of freezing (NR_90 sec) compared to the extended exposure group (NR_14 min). Exercise enhanced freezing following 90-sec exposure (R_90 sec) compared to sedentary rats (NR_90 sec), and exercise reduced levels of freezing following 14-min context reexposure, indicating enhanced extinction (R_14 min). $\left({ }^{*}\right) P<0.05,\left({ }^{* *}\right) P<0.005$. 

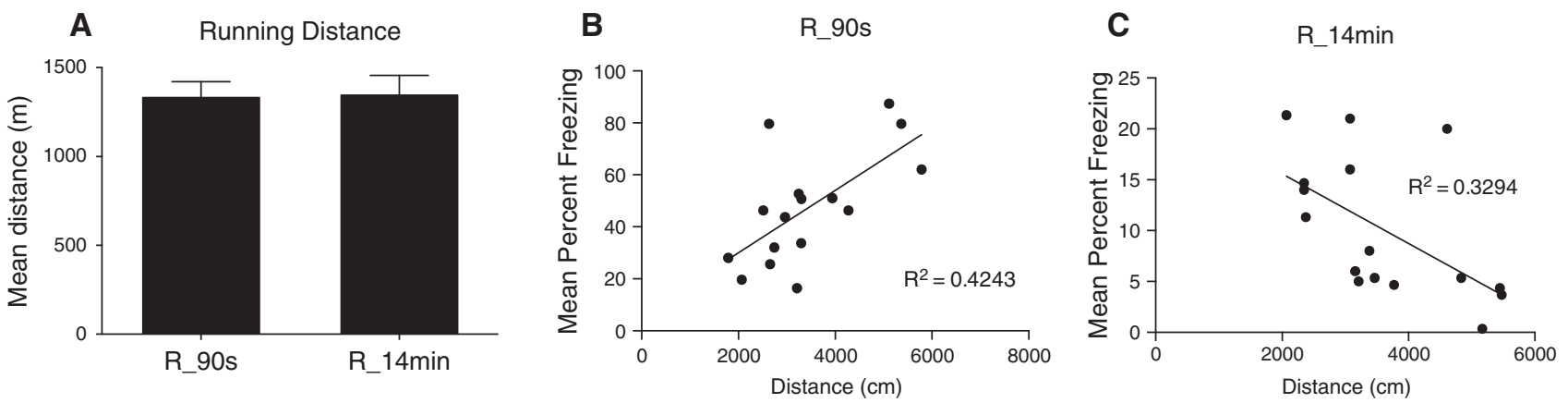

Figure 6. (A) Animals ran $\sim 2000 \mathrm{~m}$ across $3 \mathrm{~h}$ and no differences were observed between groups. (B) Running distance was positively correlated with freezing behavior in the 90-sec reexposure group (R_90 sec), indicating that greater running distances lead to increased levels of freezing, indicative of memory strengthening. (C) Running distance was negatively correlated with freezing behavior in the 14-min exposure groups (R_14 min), indicating that greater running distances lead to decreased levels of freezing, indicative of enhanced extinction.

of memory consolidation appears to be a hippocampus-dependent as opposed to an amygdala-dependent function, whereby temporary inactivation of the lateral amygdala prior to auditory fear conditioning blocked subsequent fear expression, but inactivation immediately after conditioning did not (Wilensky et al. 2000). This suggests that the lateral amygdala has a specific role in memory acquisition and may not be involved in the consolidation of Pavlovian CS-US associations.

Extinction learning involves a distributed network of brain areas centered around activity in the BLA, while consolidation recruits other circuits and brain areas (Herry et al. 2010). Memory consolidation, extinction, and reconsolidation have been shown to be dependent on activation of glutamate NMDA receptors, and physical exercise may act to augment these mechanisms (Vasuta et al. 2007). NMDA receptor antagonists have been demonstrated to disrupt the consolidation (Goeldner et al. 2009; Charlier and Tirelli 2011), extinction (Falls et al. 1992; Baker and Azorlosa 1996; Sotres-Bayon et al. 2007), and reconsolidation (Przybyslawski and Sara 1997; Ben Mamou et al. 2006; Lee et al. 2006; Charlier and Tirelli 2011) of fear memories, indicating that NMDA receptors are critically involved in memory processes. In contrast, NMDA agonists such as D-cycloserine (DCS) have been demonstrated to enhance aversive memory reconsolidation (Lee et al. 2006; Kalisch et al. 2009; Yamada et al. 2009) and facilitate extinction (Walker et al. 2002; Ledgerwood et al. 2003; Vervliet 2008). NMDA-dependent cellular mechanisms could also mediate the effects of running on consolidation of the fear memory, its extinction, and its reconsolidation. Consistent with this suggestion, exercise altered the contribution of NMDA NR2A subunits to synaptic plasticity in the dentate gyrus (Vasuta et al. 2007). Administration of the NMDA receptor antagonist MK-801 was shown to reduce both the arterial pressure and heart rate increase evoked by dynamic exercise (Camargo et al. 2013). However, the potential role of enhanced NMDA receptor activation in mediating the present results has yet to be determined, for example, by assessing whether administration of NMDA antagonists attenuate the effects of exercise in the consolidation, reconsolidation, and extinction of an aversive memory.

Finally, the single bout of running may have increased arousal or acted as a mild stressor, increasing hypothalamic-pituitaryadrenal (HPA) axis activation through corticosteroid release (Petrides et al. 1994; Stranahan et al. 2008). HPA-axis activation via arousal or through changes to homeostasis due to the metabolic demands of running initiates hormonal and neurotransmitter release throughout the brain and this can modulate learning and memory processes, including those involved in consolidation, reconsolidation, and extinction. Voluntary exercise has been dem- onstrated to enhance the capacity for excitatory synaptic transmissions in the hippocampus and these, in turn, can influence plasticity (Stranahan et al. 2008). Consolidation processes are typically enhanced by arousal, and evidence from human and rodent studies demonstrates that stress or glucocorticoid administration within a short time window after learning facilitates subsequent memory (Roozendaal and McGaugh 1996; Buchanan and Lovallo 2001; Cahill et al. 2003; Andreano and Cahill 2006; Roozendaal et al. 2006). In addition, stress and glucocorticoid administration after memory retrieval impair later recall (Cai et al. 2006; Maroun and Akirav 2008; Schwabe and Wolf 2010), indicating that arousal can impact upon reconsolidation and/or extinction processes. Pharmacological evidence also indicates the involvement of noradrenalin (norepinephrine) in emotional memory consolidation (Cahill et al. 1994; O'Carroll et al. 1999; Soeter and Kindt 2012b) and reconsolidation (Debiec et al. 2011; Soeter and Kindt 2012a). Physical exercise has been demonstrated to induce noradrenergic activity through activation of the locus coeruleus (LC) (Dishman et al. 2000). The LC densely innervates limbic structures involved in consolidation of long-term memory, including the hippocampus and amygdala (Sara 2009). Noradrenergic projections have been indicated to modulate hippocampal synaptic plasticity (Neuman and Harley 1983; Harley 2007) and exerts influence on memory consolidation (Mueller and Cahill 2010; McIntyre et al. 2012) and reconsolidation (Debiec and LeDoux 2004) through binding of noradrenalin to $\beta$-adrenergic receptors within the BLA and hippocampus. Furthermore, the $\alpha 2$ adrenoreceptor antagonist yohimbine, which enhances noradrenalin release and increases sympathetic activity, has been shown to evoke panic attacks and anxiety, but also to enhance extinction of conditioned fear (Cain et al. 2004). The infralimbic PFC (IL PFC) receives direct innervation from the $\mathrm{LC}$ and noradrenergic signaling in this region has a modulatory role in extinction neurocircuitry (Mueller et al. 2008). Exercise-evoked increase in noradrenergic activity within the LC therefore provides another potential mechanism of plasticity modulation.

Our results contrast previous observations by Greenwood et al. (2009) who reported that access to running wheels did not influence the rate at which the rats extinguished conditioned fear, despite apparently enhanced consolidation of a contextshock memory. Prolonged access to running wheels has been shown to have anxiolytic effects in laboratory rodents (Duman et al. 2008; Greenwood et al. 2008; Sciolino and Holmes 2012), whereas the effects of acute exercise on anxiety levels are less clear (Youngstedt et al. 1993). Thus, in Greenwood's (2009) study, extinction of a context fear memory may not have been affected by running access as rats exposed to chronic exercise were less 
anxious or had lower levels of arousal following extinction training and therefore did not show enhanced extinction. In contrast, acute exercise prior to or immediately following extinction training may have increased general arousal levels and enhance extinction consolidation. The present experiments differed from those conducted by Greenwood et al. (2009) in that the wheels were provided for a limited period before or after the extinction session here, whereas the wheels were available continuously in the previous studies. It is possible that the single bout of running constituted a novel and discrete episode whose close proximity to the extinction episode enabled enhanced extinction consolidation in the current study. However, the continuous access to the wheels may not have occurred sufficiently close in proximity or may have been so distributed in time after the extinction as to have failed to influence consolidation processes in the previous studies.

The contrasting effects of running immediately after a brief or extended nonshocked exposure to the conditioned context are consistent with the proposal that the duration of the memory reactivation and extinction training sessions serves as a critical parameter that separates reconsolidation and extinction (Eisenberg et al. 2003; Pedreira and Maldonado 2003; Suzuki et al. 2004; Reichelt and Lee 2012). When the reactivation session is brief, reconsolidation processes are dominant, whereas longer sessions induce extinction mechanisms. Supporting the previous observations by Lee et al. (2006), our current investigation found that a brief reexposure to the context enhanced reconsolidation of the conditioning memory and facilitated learning of this context at test. This is the first demonstration that exercise modulated subsequent expression of fear following a brief or extended reexposure to the context in extinction. An enhancement of the reconsolidation effect for the brief exposure and an improvement in extinction learning in the long exposure was found. Thus, once reactivated, a consolidated fear memory undergoes a labile phase during which it is sensitive to modulation, and may be disrupted by the systemic or localized application of amnesic agents (Przybyslawski and Sara 1997; Nader et al. 2000; Ben Mamou et al. 2006; Lee et al. 2006; Charlier and Tirelli 2011), or can be strengthened by NMDA agonists (Lee et al. 2006; Kelley et al. 2007; Yamada et al. 2009; PorteroTresserra et al. 2013), and, as shown in our current experiment, enhanced by running.

Interestingly, dissociation between the requirements of BDNF has been observed in the consolidation and reconsolidation of long-term memories (Lee et al. 2004); specifically, BDNF was required in the initial consolidation of cue-fear memories, but not in their reconsolidation, which was shown to be Zif268 dependent. In light of our current findings, it may be tentatively suggested that exercise not only enhances BDNF, but may impact upon other brain transcription factors, such as Zif268 and upstream factors of de novo protein synthesis, where diverging pathways of hippocampal contextual fear memory consolidation and reconsolidation have been observed. It has been demonstrated that the dissociation between BDNF and Zif268 expression in memory consolidation and reconsolidation extends to the selective requirement for separate plasticity-associated gene expression of
MEK and IKK $\alpha$ protein kinases, respectively, and a common involvement of NMDA receptors (Lee and Hynds 2013).

In conclusion, the effects of voluntary exercise on the learning and memory of context fear conditioning was examined in these studies, and we revealed specific and significant enhancements in fear acquisition, extinction, and reconsolidation. These data provide the first evidence that a short bout of physical activity prior to or immediately following conditioning or context reexposure is capable of enhancing memory processes. This evidence may provide the basis for new therapeutic interventions to facilitate extinction learning and cognitive-behavioral therapies for psychiatric disorders such as post-traumatic stress disorders.

\section{Materials and Methods}

Figure 7 shows the time line of these experiments.

\section{Experiment 1: effect of wheel running on consolidation of conditioned fear}

\section{Subjects}

Animals were 32 experimentally naïve 6 -wk-old Wistar male rats, obtained from a commercial supplier (Australian Research Centre, Perth), weighing between 280 and 310 g. Rats were housed in groups of four in plastic boxes $(23 \mathrm{~cm}$ deep $\times 21 \mathrm{~cm}$ wide $\times 23$ $\mathrm{cm}$ high) on woodchip bedding, and kept in an air-conditioned colony room $\left(21^{\circ} \mathrm{C}\right)$ under a 12-h light-dark cycle (lights on from 7 a.m. to 7 p.m.). Food and water were continuously available in the home cage during all phases of the experiments. Experimental procedures were carried out between 9 a.m. and 5 p.m. Rats weighed between 300 and $340 \mathrm{~g}$ at the beginning of the experiment. Each rat was handled for $\sim 2-3$ min each day for $4 \mathrm{~d}$ prior to the start of the experiment. These procedures are consistent with the ethical guidelines established by the American Psychology Association and were approved by the Animal Care and Ethics Committee of the University of New South Wales.
A
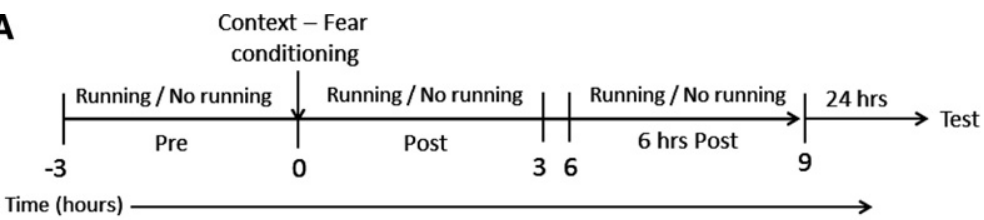

B
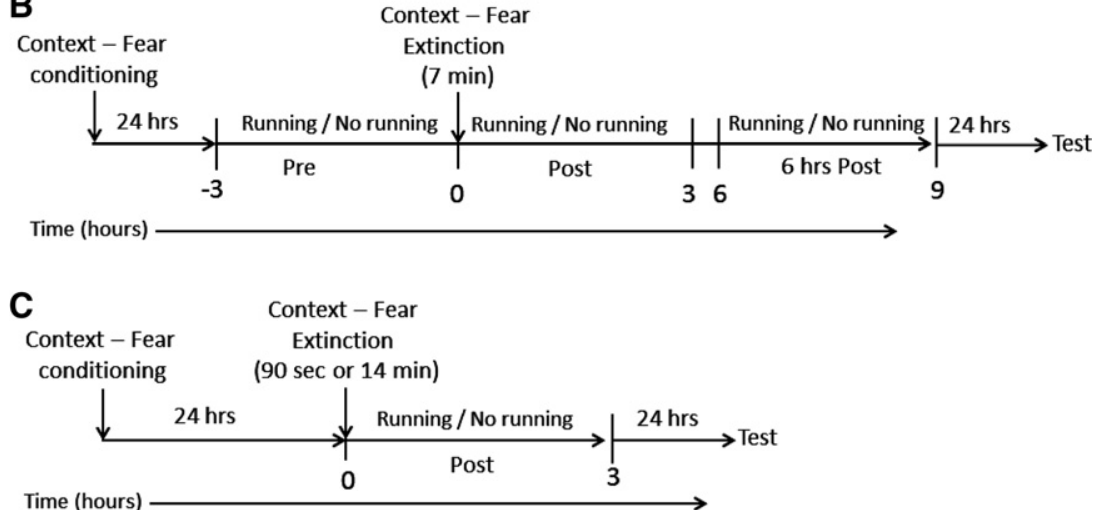

Figure 7. Schematic illustration of the time-course for Experiment $1(A)$, Experiment $2(B)$, and Experiment $3(C)$, indicating when access to running wheels was available. 


\section{Apparatus}

The apparatus consisted of a set of four identical conditioning chambers measuring $19.5 \mathrm{~cm}$ high $\times 23.5 \mathrm{~cm}$ long $\times 20.5 \mathrm{~cm}$ wide. The sidewalls and ceiling were made of aluminum, and the back and front walls were made of clear Perspex. The floor of each chamber consisted of stainless-steel rods, $2 \mathrm{~mm}$ wide, spaced $10 \mathrm{~mm}$ apart, with a tray below containing sawdust bedding. Each chamber was enclosed in a sound- and light-attenuating cabinet. A custom-built constant-current shock generator, capable of delivering unscrambled AC $50-\mathrm{Hz}$ shock to the floor of each chamber, was used for the presentation of a 0.5 -sec, $0.8-\mathrm{mA}$ footshock US. The floor of each chamber was cleaned with water prior to training to minimize olfactory cues. Illumination for each chamber was provided by an infrared light source $(940 \pm 25 \mathrm{~nm})$ and an infrared camera mounted on the back wall of each shell was used to record the behavior of each rat. Each camera was connected to a monitor and a DVD recorder located in another room of the laboratory. This room contained the computer that controlled stimulus presentations via appropriate software (LabView, National Instruments). Background noise was $\sim 45 \mathrm{~dB}$, measured by a digital sound level meter (Dick Smith Electronics).

Running wheels were made out of plastic with a solid running surface, measuring 11 inches in diameter and 3 inches deep (Wodent Wheels). Each wheel had a magnetic clip attached at the rear of the wheel which activated an adjacent counter for measuring the number of wheel rotations. There were two wheels and four animals per home cage. Animals and wheels were labeled to allow for scoring of video recordings of animals' individual exercise patterns. In nonrunning groups a wheel was present but in a locked position to prevent running, but provided a novel exploratory object.

\section{Procedure}

On Day 1, all rats were familiarized with the conditioning chambers across two 5 -min exposures separated by $3 \mathrm{~h}$. On Day 2, each rat was placed into a chamber and administered a single, unsignaled 0.5 -sec, $0.8-\mathrm{mA}$ footshock after $5 \mathrm{~min}$. Rats remained in the chamber for a further $3 \mathrm{~min}$. They were then removed and returned to their home cages in the colony room. Rats in Group R-Pre were provided with running wheels in their home cages for $3 \mathrm{~h}$ immediately before this shocked exposure to the chamber. Those in Group R-Post received 3-h access to the wheels after the shocked exposure to the context, while those in Group R-Post $6 \mathrm{~h}$ were provided with wheels $6 \mathrm{~h}$ after the shocked exposure. Finally, rats in Group NR did not receive access to the wheels. On Day 2, rats were returned to the chamber and tested for their levels of freezing under extinction. The duration of the test was $10 \mathrm{~min}$.

\section{Experiment 2: effect of wheel running on extinction of conditioned fear}

\section{Subjects and apparatus}

The subjects were 32 experimentally naïve rats of the same strain, sex, age, and weight, obtained from the same source, and kept under the same conditions as in the previous experiment. The same apparatus was used as in Experiment 1.

\section{Procedure}

On Day 1, all rats received two 5-min exposures, separated by $3 \mathrm{~h}$, to the conditioning chambers. On Day 2, each rat was placed into a chamber and administered a single, unsignaled 0.5-sec, $0.8-\mathrm{mA}$ footshock after $5 \mathrm{~min}$. Rats remained in the chamber for a further $3 \mathrm{~min}$ and then returned to home cages. On Day 3, each rat was exposed to the conditioning chamber for $7 \mathrm{~min}$ in the absence of shock. This duration was selected so as to preclude complete extinction and thereby allow the detection of any differences among the groups on the subsequent test. One group of rats was given wheel access prior to the extinction session (Group R-Pre). Two groups of rats were given wheel access after extinction; one of which had access immediately (Group R-Post) and the other had access $6 \mathrm{~h}$ after extinction (Group R-Post $6 \mathrm{~h}$ ). The duration of wheel access was $3 \mathrm{~h}$. The fourth group (Group NR) did not receive access to the wheels. On Day 4 , all rats were tested. The duration of the test was $10 \mathrm{~min}$ and no footshocks were administered.

\section{Experiment 3: effect of wheel running on reconsolidation of conditioned fear}

\section{Subjects and apparatus}

The subjects were 48 experimentally naïve male rats of the same age, weight, sex, and strain, obtained from the same source as in the previous experiments. The same apparatus was used as in Experiment 1.

\section{Procedure}

On Day 1, all rats received two 5-min exposures, separated by $3 \mathrm{~h}$, to the conditioning chambers. On Day 2, conditioning was administered in the same manner as previously described. Rats were placed in the conditioning chamber for $5 \mathrm{~min}$ before a $0.8-\mathrm{mA}, 0.5$-sec shock was delivered. Animals remained in the chambers for a further $3 \mathrm{~min}$ prior to being returned to their home cages. On Day 3, an additional conditioning session was administered to all animals in order to ensure substantial fear conditioning and the detection of differences on the final test between rats given brief or extended nonshocked exposures to the conditioned context. Animals were placed in the chamber for $1 \mathrm{~min}$ prior to receiving a $0.8-\mathrm{mA}, 0.5-\mathrm{sec}$ shock. They remained in the chambers for an additional $3 \mathrm{~min}$ and were then later returned to their home cages. This second conditioning session was conducted in the manner described in an attempt to avoid the timing effect that appeared to characterize their extinction performance following the initial conditioning session. On Day 4 , half of the animals were exposed to the chambers for $90 \mathrm{sec}$ (Group $90 \mathrm{sec}$ ), and the remainder exposed for $14 \mathrm{~min}$ (Group $14 \mathrm{~min}$ ). Following either these brief or extended exposures, half of the rats in each group were provided with access to wheels for $3 \mathrm{~h}$ whereas the remainder were not provided with access to wheels. On Day 5, all animals were exposed for a 10-min test exposure to the chamber.

\section{Scoring and statistics}

The behavior of each rat was recorded onto DVD and then scored to determine the levels of freezing. A time sampling procedure was used in which the behavior of each rat was scored as freezing or not freezing every $2 \mathrm{sec}$. Freezing was defined as the absence of all movements except those related to breathing (Fanselow 1980). The number of occasions on which the behavior was scored as freezing was expressed as a percentage of the total number of observations. Two observers, one of whom was naïve to the group allocation, scored the DVDs. The correlation between their scores in this and the remaining experiments was high, $r>0.91$. The data in this and the remaining experiments were analyzed with planned contrasts which used the Bonferroni inequality to control $\alpha=0.05$ for the number of contrasts tested.

\section{Acknowledgments}

This research was supported by an Australian Postgraduate Research Scholarship to J.S. and an Australian Research Council Discovery Project DP110105136 to R.F.W.

\section{References}

Andreano JM, Cahill L. 2006. Glucocorticoid release and memory consolidation in men and women. Psychol Sci 17: 466-470.

Baker JD, Azorlosa JL. 1996. The NMDA antagonist MK-801 blocks the extinction of Pavlovian fear conditioning. Behav Neurosci 110: $618-620$. 
Baruch DE, Swain RA, Helmstetter FJ. 2004. Effects of exercise on Pavlovian fear conditioning. Behav Neurosci 118: 1123-1127.

Ben Mamou C, Gamache K, Nader K. 2006. NMDA receptors are critical for unleashing consolidated auditory fear memories. Nat Neurosci 9: $1237-1239$.

Bourtchouladze R, Abel T, Berman N, Gordon R, Lapidus K, Kandel ER. 1998. Different training procedures recruit either one or two critical periods for contextual memory consolidation, each of which requires protein synthesis and PKA. Learn Mem 5: 365-374.

Bouton ME, Mineka S, Barlow DH. 2001. A modern learning theory perspective on the etiology of panic disorder. Psychol Rev 108: 4-32.

Buchanan TW, Lovallo WR. 2001. Enhanced memory for emotional material following stress-level cortisol treatment in humans. Psychoneuroendocrinology 26: 307-317.

Burghardt PR, Fulk LJ, Hand GA, Wilson MA. 2004. The effects of chronic treadmill and wheel running on behavior in rats. Brain Res 1019: $84-96$.

Burghardt PR, Pasumarthi RK, Wilson MA, Fadel J. 2006. Alterations in fear conditioning and amygdalar activation following chronic wheel running in rats. Pharmacol Biochem Behav 84: 306-312.

Cahill L, Prins B, Weber M, McGaugh JL. 1994. $\beta$-Adrenergic activation and memory for emotional events. Nature 371: 702-704.

Cahill L, Gorski L, Le K. 2003. Enhanced human memory consolidation with post-learning stress: Interaction with the degree of arousal at encoding. Learn Mem 10: 270-274.

Cai WH, Blundell J, Han J, Greene RW, Powell CM. 2006. Postreactivation glucocorticoids impair recall of established fear memory. J Neurosci $\mathbf{2 6}$ : 9560-9566.

Cain CK, Blouin AM, Barad M. 2004. Adrenergic transmission facilitates extinction of conditional fear in mice. Learn Mem 11: 179-187.

Camargo LH, Alves FH, Biojone C, Correa FM, Resstel LB, Crestani CC. 2013. Involvement of N-methyl-D-aspartate glutamate receptor and nitric oxide in cardiovascular responses to dynamic exercise in rats. Eur J Pharmacol 713: $16-24$

Charlier Y, Tirelli E. 2011. Differential effects of histamine $\mathrm{H}_{3}$ receptor inverse agonist thioperamide, given alone or in combination with the $\mathrm{N}$-methyl-D-aspartate receptor antagonist dizocilpine, on reconsolidation and consolidation of a contextual fear memory in mice. Neuroscience 193: 132-142.

Clark PJ, Brzezinska WJ, Thomas MW, Ryzhenko NA, Toshkov SA, Rhodes JS. 2008. Intact neurogenesis is required for benefits of exercise on spatial memory but not motor performance or contextual fear conditioning in C57BL/6J mice. Neuroscience 155: 1048-1058.

Coles K, Tomporowski PD. 2008. Effects of acute exercise on executive processing, short-term and long-term memory. J Sports Sci 26: 333-344

Debiec J, LeDoux JE. 2004. Disruption of reconsolidation but not consolidation of auditory fear conditioning by noradrenergic blockade in the amygdala. Neuroscience 129: 267-272.

Debiec J, Bush DE, LeDoux JE. 2011. Noradrenergic enhancement of reconsolidation in the amygdala impairs extinction of conditioned fear in rats-a possible mechanism for the persistence of traumatic memories in PTSD. Depress Anxiety 28: 186-193.

Dishman RK, Renner KJ, White-Welkley JE, Burke KA, Bunnell BN. 2000. Treadmill exercise training augments brain norepinephrine response to familiar and novel stress. Brain Res Bull 52: $337-342$.

Duman CH, Schlesinger L, Russell DS, Duman RS. 2008. Voluntary exercise produces antidepressant and anxiolytic behavioral effects in mice. Brain Res 1199: 148-158.

Duvarci S, Nader K. 2004. Characterization of fear memory reconsolidation. J Neurosci 24: 9269-9275.

Eisenberg M, Kobilo T, Berman DE, Dudai Y. 2003. Stability of retrieved memory: Inverse correlation with trace dominance. Science 301: 1102-1104.

Falls WA, Miserendino MJ, Davis M. 1992. Extinction of fear-potentiated startle: Blockade by infusion of an NMDA antagonist into the amygdala. J Neurosci 12: 854-863.

Fanselow MS. 1980. Conditioned and unconditional components of post-shock freezing. Pavlov J Biol Sci 15: 177-182.

Goeldner C, Reiss D, Wichmann J, Kieffer BL, Ouagazzal AM. 2009. Activation of nociceptin opioid peptide (NOP) receptor impairs contextual fear learning in mice through glutamatergic mechanisms. Neurobiol Learn Mem 91: 393-401.

Gomes da Silva S, Unsain N, Masco DH, Toscano-Silva M, de Amorim HA, Silva Araujo BH, Simoes PS, Naffah-Mazzacoratti Mda G, Mortara RA, Scorza FA, et al. 2012. Early exercise promotes positive hippocampal plasticity and improves spatial memory in the adult life of rats. Hippocampus 22: 347-358.

Greenwood BN, Kennedy S, Smith TP, Campeau S, Day HE, Fleshner M. 2003. Voluntary freewheel running selectively modulates catecholamine content in peripheral tissue and c-Fos expression in the central sympathetic circuit following exposure to uncontrollable stress in rats. Neuroscience 120: $269-281$.
Greenwood BN, Strong PV, Brooks L, Fleshner M. 2008. Anxiety-like behaviors produced by acute fluoxetine administration in male Fischer 344 rats are prevented by prior exercise. Psychopharmacology 199: 209-222.

Greenwood BN, Strong PV, Foley TE, Fleshner M. 2009. A behavioral analysis of the impact of voluntary physical activity on hippocampus-dependent contextual conditioning. Hippocampus 19: $988-1001$.

Greenwood BN, Foley TE, Le TV, Strong PV, Loughridge AB, Day HE, Fleshner M. 2011. Long-term voluntary wheel running is rewarding and produces plasticity in the mesolimbic reward pathway. Behav Brain Res 217: 354-362.

Harley CW. 2007. Norepinephrine and the dentate gyrus. Prog Brain Res 163: 299-318.

Herry C, Ferraguti F, Singewald N, Letzkus JJ, Ehrlich I, Luthi A. 2010 Neuronal circuits of fear extinction. Eur J Neurosci 31: 599-612.

Kalisch R, Holt B, Petrovic P, De Martino B, Kloppel S, Buchel C, Dolan RJ. 2009. The NMDA agonist D-cycloserine facilitates fear memory consolidation in humans. Cereb Cortex 19: 187-196.

Kelley JB, Anderson KL, Itzhak Y. 2007. Long-term memory of cocaine-associated context: Disruption and reinstatement. Neuroreport 18: $777-780$.

Kohman RA, Rodriguez-Zas SL, Southey BR, Kelley KW, Dantzer R, Rhodes JS. 2011. Voluntary wheel running reverses age-induced changes in hippocampal gene expression. PLoS One 6: e22654.

Ledgerwood L, Richardson R, Cranney J. 2003. Effects of D-cycloserine on extinction of conditioned freezing. Behav Neurosci 117: 341-349.

Lee JL. 2009. Reconsolidation: Maintaining memory relevance. Trends Neurosci 32: 413-420.

Lee JL, Hynds RE. 2013. Divergent cellular pathways of hippocampal memory consolidation and reconsolidation. Hippocampus 23: 233-244.

Lee JL, Everitt BJ, Thomas KL. 2004. Independent cellular processes for hippocampal memory consolidation and reconsolidation. Science 304: $839-843$.

Lee JL, Milton AL, Everitt BJ. 2006. Reconsolidation and extinction of conditioned fear: Inhibition and potentiation. J Neurosci 26: $10051-10056$

Liu YF, Chen HI, Yu L, Kuo YM, Wu FS, Chuang JI, Liao PC, Jen CJ. 2008. Upregulation of hippocampal TrkB and synaptotagmin is involved in treadmill exercise-enhanced aversive memory in mice. Neurobiol Learn Mem 90: 81-89.

Maroun M, Akirav I. 2008. Arousal and stress effects on consolidation and reconsolidation of recognition memory. Neuropsychopharmacology 33: $394-405$.

McIntyre CK, McGaugh JL, Williams CL. 2012. Interacting brain systems modulate memory consolidation. Neurosci Biobehav Rev 36: $1750-1762$.

Mueller D, Cahill SP. 2010. Noradrenergic modulation of extinction learning and exposure therapy. Behav Brain Res 208: 1-11.

Mueller D, Porter JT, Quirk GJ. 2008. Noradrenergic signaling in infralimbic cortex increases cell excitability and strengthens memory for fear extinction. J Neurosci 28: 369-375.

Nader K, Schafe GE, Le Doux JE. 2000. Fear memories require protein synthesis in the amygdala for reconsolidation after retrieval. Nature 406: $722-726$.

Neeper SA, Gomez-Pinilla F, Choi J, Cotman CW. 1996. Physical activity increases mRNA for brain-derived neurotrophic factor and nerve growth factor in rat brain. Brain Res 726: 49-56.

Neuman RS, Harley CW. 1983. Long-lasting potentiation of the dentate gyrus population spike by norepinephrine. Brain Res 273: 162-165.

O'Callaghan RM, Ohle R, Kelly AM. 2007. The effects of forced exercise on hippocampal plasticity in the rat: A comparison of LTP, spatial- and non-spatial learning. Behav Brain Res 176: 362-366.

O'Carroll RE, Drysdale E, Cahill L, Shajahan P, Ebmeier KP. 1999. Stimulation of the noradrenergic system enhances and blockade reduces memory for emotional material in man. Psychol Med 29: $1083-1088$.

Pedreira ME, Maldonado H. 2003. Protein synthesis subserves reconsolidation or extinction depending on reminder duration. Neuron 38: $863-869$

Petrides JS, Mueller GP, Kalogeras KT, Chrousos GP, Gold PW, Deuster PA. 1994. Exercise-induced activation of the hypothalamic-pituitaryadrenal axis: Marked differences in the sensitivity to glucocorticoid suppression. J Clin Endocrinol Metab 79: 377-383.

Portero-Tresserra M, Marti-Nicolovius M, Guillazo-Blanch G, Boadas-Vaello P, Vale-Martinez A. 2013. D-Cycloserine in the basolateral amygdala prevents extinction and enhances reconsolidation of odor-reward associative learning in rats. Neurobiol Learn Mem 100: 1-11.

Przybyslawski J, Sara SJ. 1997. Reconsolidation of memory after its reactivation. Behav Brain Res 84: $241-246$. 
Rasmussen P, Brassard P, Adser H, Pedersen MV, Leick L, Hart E, Secher NH, Pedersen BK, Pilegaard H. 2009. Evidence for a release of brain-derived neurotrophic factor from the brain during exercise. Exp Physiol 94: $1062-1069$

Reichelt AC, Lee JL. 2012. Appetitive Pavlovian goal-tracking memories reconsolidate only under specific conditions. Learn Mem 20: 51-60.

Roig M, Skriver K, Lundbye-Jensen J, Kiens B, Nielsen JB. 2012. A single bout of exercise improves motor memory. PLoS One 7: e44594.

Roozendaal B, McGaugh JL. 1996. The memory-modulatory effects of glucocorticoids depend on an intact stria terminalis. Brain Res 709: $243-250$.

Roozendaal B, Okuda S, Van der Zee EA, McGaugh JL. 2006. Glucocorticoid enhancement of memory requires arousal-induced noradrenergic activation in the basolateral amygdala. Proc Natl Acad Sci 103: $6741-6746$.

Sara SJ. 2000. Retrieval and reconsolidation: Toward a neurobiology of remembering. Learn Mem 7: 73-84.

Sara SJ. 2009. The locus coeruleus and noradrenergic modulation of cognition. Nat Rev Neurosci 10: 211-223.

Schwabe L, Wolf OT. 2010. Learning under stress impairs memory formation. Neurobiol Learn Mem 93: 183-188.

Sciolino NR, Holmes PV. 2012. Exercise offers anxiolytic potential: A role for stress and brain noradrenergic-galaninergic mechanisms. Neurosci Biobehav Rev 36: 1965-1984.

Segal SK, Cotman CW, Cahill LF. 2012. Exercise-induced noradrenergic activation enhances memory consolidation in both normal aging and patients with amnestic mild cognitive impairment. J Alzheimers Dis 32: 1011-1018.

Shimizu E, Tang YP, Rampon C, Tsien JZ. 2000. NMDA receptor-dependent synaptic reinforcement as a crucial process for memory consolidation. Science 290: 1170-1174.

Soeter M, Kindt M. 2012a. Erasing fear for an imagined threat event. Psychoneuroendocrinology 37: 1769-1779.

Soeter M, Kindt M. 2012b. Stimulation of the noradrenergic system during memory formation impairs extinction learning but not the disruption of reconsolidation. Neuropsychopharmacology 37: 1204-1215.

Sotres-Bayon F, Bush DE, LeDoux JE. 2007. Acquisition of fear extinction requires activation of NR2B-containing NMDA receptors in the lateral amygdala. Neuropsychopharmacology 32: 1929-1940.

Stranahan AM, Lee K, Mattson MP. 2008. Central mechanisms of HPA axis regulation by voluntary exercise. Neuromolecular Med 10: 118-127.
Strong PV, Christianson JP, Loughridge AB, Amat J, Maier SF, Fleshner M, Greenwood BN. 2011. 5-Hydroxytryptamine 2C receptors in the dorsal striatum mediate stress-induced interference with negatively reinforced instrumental escape behavior. Neuroscience 197: 132-144.

Suzuki A, Josselyn SA, Frankland PW, Masushige S, Silva AJ, Kida S. 2004. Memory reconsolidation and extinction have distinct temporal and biochemical signatures. J Neurosci 24: 4787-4795.

Van Hoomissen JD, Holmes PV, Zellner AS, Poudevigne A, Dishman RK. 2004. Effects of $\beta$-adrenoreceptor blockade during chronic exercise on contextual fear conditioning and mRNA for galanin and brain-derived neurotrophic factor. Behav Neurosci 118: 1378-1390.

van Praag H, Kempermann G, Gage FH. 1999. Running increases cell proliferation and neurogenesis in the adult mouse dentate gyrus. Nat Neurosci 2: 266-270.

van Praag H, Shubert T, Zhao C, Gage FH. 2005. Exercise enhances learning and hippocampal neurogenesis in aged mice. J Neurosci 25: 8680-8685.

Vasuta C, Caunt C, James R, Samadi S, Schibuk E, Kannangara T, Titterness AK, Christie BR. 2007. Effects of exercise on NMDA receptor subunit contributions to bidirectional synaptic plasticity in the mouse dentate gyrus. Hippocampus 17: 1201-1208.

Vaynman S, Ying Z, Gomez-Pinilla F. 2004. Hippocampal BDNF mediates the efficacy of exercise on synaptic plasticity and cognition. Eur J Neurosci 20: 2580-2590.

Vervliet B. 2008. Learning and memory in conditioned fear extinction: Effects of D-cycloserine. Acta Psychol (Amst) 127: 601-613.

Walker DL, Ressler KJ, Lu KT, Davis M. 2002. Facilitation of conditioned fear extinction by systemic administration or intra-amygdala infusions of D-cycloserine as assessed with fear-potentiated startle in rats. J Neurosci 22: $2343-2351$.

Wilensky AE, Schafe GE, LeDoux JE. 2000. The amygdala modulates memory consolidation of fear-motivated inhibitory avoidance learning but not classical fear conditioning. J Neurosci 20: 7059-7066.

Yamada D, Zushida K, Wada K, Sekiguchi M. 2009. Pharmacological discrimination of extinction and reconsolidation of contextual fear memory by a potentiator of AMPA receptors. Neuropsychopharmacology 34: $2574-2584$.

Youngstedt SD, Dishman RK, Cureton KJ, Peacock LJ. 1993. Does body temperature mediate anxiolytic effects of acute exercise? J Appl Physiol 74: $825-831$.

Received July 21, 2013; accepted in revised form October 24, 2013. 


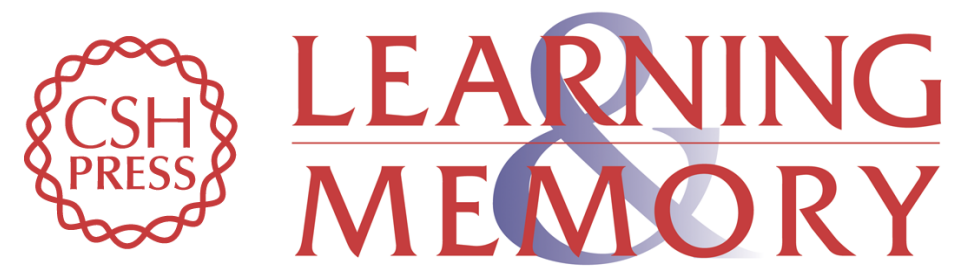

\section{A bout of voluntary running enhances context conditioned fear, its extinction, and its reconsolidation}

Joyce Siette, Amy C. Reichelt and R. Frederick Westbrook

Learn. Mem. 2014, 21:

Access the most recent version at doi:10.1101/Im.032557.113

References This article cites 82 articles, 18 of which can be accessed free at: http://learnmem.cshlp.org/content/21/2/73.full.html\#ref-list-1

Creative This article is distributed exclusively by Cold Spring Harbor Laboratory Press for the Commons License first 12 months after the full-issue publication date (see

http://learnmem.cshlp.org/site/misc/terms.xhtml). After 12 months, it is available under a Creative Commons License (Attribution-NonCommercial 3.0 Unported), as described at http://creativecommons.org/licenses/by-nc/3.0/.

Email Alerting Receive free email alerts when new articles cite this article - sign up in the box at the Service top right corner of the article or click here. 